\title{
The effects of carbon nanotubes added polyvinyl alcohol nanofibers on mechanical properties of carbon reinforced composite laminates
}

\author{
MÜRSEL EKREM® \\ Department of Mechanical Engineering, Necmettin Erbakan University, Konya, Turkey \\ e-mail: mekrem@erbakan.edu.tr
}

MS received 15 October 2018; revised 11 April 2019; accepted 29 May 2019

\begin{abstract}
This study investigates tensile and flexural behaviors of carbon fiber reinforced epoxy (CFRE) composite laminates strengthened in different weights multi walled carbon nanotubes (MWCNT) with/without polyvinyl alcohol (PVA) nanofiber mats. First, PVA nanofiber mats modified with 1, 3, $5 \mathrm{wt} \%$ MWCNT were produced by electro spinning. Characterization of 1, 3 and 5 MWCNT reinforced/unreinforced PVA nanofiber mats was achieved via transmission electron microscopy (TEM) and scanning electron microscopy (SEM). Then, the produced nanofiber mats were placed in the middle of eight-layer twill carbon fabrics by hand layup after carbon composites were produced by vacuum infusion. Three flexural tests were performed in accordance with ASTM D 7264/D standard so that flexural strength properties of the composites and flexural modulus of elasticity can be found. After that, tensile test was carried out in accordance with ASTM D 3039 for the composites to have single axis tensile strength and modulus of elasticity nanofibers. The tensile strengths of PVA nanofiber mats and $1 \mathrm{wt} \%$ MWCNT/PVA nanofiber mats reinforced CFRE composites increased by $4 \%$ and $34 \%$, respectively when compared to the CFRE composite.
\end{abstract}

Keywords. Composites; nanofibers; electrospinning; tensile strength; nanoparticles.

\section{Introduction}

Today, polymer matrix composite materials are utilized in a number of areas in advanced engineering applications and also in conventional technologies. Because of both performance increase and lightness advantage, the use of composite material instead of conventional materials offers advantages such as corrosion resistance, high stiffness and high strength. In spite of these properties, polymer matrix composites usually suffer from poor delamination strength, fracture toughness and impact resistance. This case is particularly when thermosetting resins are utilize as a composite matrix [1].

With high strength/weight and stiffness/weight ratios, elastic modulus, high fracture toughness and good insulating properties carbon fiber reinforced epoxy (CFRE) composites have been widely used as structural materials for space and aviation, and automotive applications [2]. However, the inherent brittleness of the epoxy matrix has lined off their wider applications and interlaminar delamination is the predominant failure mode of these high performance epoxy composite laminates [3]. Many strategies have been improved to overcome this problem, and one of the most popular methods is interleaving, whereby a discrete interlayer (either thermoplastic or thermoset) is inserted between adjacent plies. The interleaves facilitate the formation of mechanical linkages between tortuous crack paths and crack interfaces, growing delamination fracture toughness of the polymeric composite laminates [4]. Many varieties of interleaves exist that include nanopaper [5], nanowires [6], films [7], nanoparticles [8,9] and nanofiber membranes [10] used in carbon fiber reinforced polymer composites. Electrospun nanofiber mat is a good candidate because of its unique properties, such as high specific surface area and large porosity, which facilitate easy diffusion of epoxy resin in processing the interleaved composite laminates.

Many kinds of nanofibers membranes were used for interlaminar toughening of composite laminates, e.g., nanofibers based on polyvinyl alcohol (PVA) [11-13], polyamide [14], polysulfone [15], polyacrylonitrile [16] and polycaprolactone [17]. Electrospun thermoplastic nanofiber mats have been shown to have a positive influence on the in-plane mechanical properties of laminates such as increasing delamination and reducing impact damage onset life [18]. It has also been shown that certain nanofiber mats can be used to improve the compression after impact [19], the Mode I and Mode II interlaminar fracture toughness and delamination resistance [20, 21], vibration damping [22] and the fatigue resistance [21] properties of fiber reinforced polymer composite laminates. Thermal properties of PVA nanofiber mats reinforced with MWCNT were also studied [23]. 
This article gives thorough insight into the flexural and tensile properties and delamination behavior of electrospun nanofiber mats interleaved composite laminates. Nanofiber mats weight $1,3,5 \%$ of MWCNT reinforced/unreinforced PVA produced by electrospun since these systems have proven their effectiveness under static loading conditions [24]. In addition, scanning electron microscope (SEM) and transmission electron microscope (TEM) images have been investigated to determine the physical properties of MWCNT reinforced/unreinforced PVA nanofiber mats. Three flexural tests were performed in accordance with ASTM D 7264/D standard to study the flexural properties. Tensile test were carried out in accordance with ASTM D 3039 standard so that tensile properties of the CFRE composite laminates strengthened in different weights multiwalled carbon nanotubes (MWCNT) with/without polyvinyl alcohol (PVA) nanofiber mats.

\section{Experimental}

\subsection{Materials}

MWCNT manufactured by NANOCYL Company through chemical vapor accumulation method was used in the present study. Diameter is 5 to $50 \mathrm{~nm}$ and the length is 10 to $30 \mu \mathrm{m}$. Closed formula of PVA is [- $\left.\mathrm{CH}_{2} \mathrm{CHOH}-\right] \mathrm{n}$ and molecular weight is $124000 \mathrm{~g} / \mathrm{mole}$. It was supplied by Sigma Aldrich Company. Sodium dodecyl sulphate (SDS) with a closed formula of $\mathrm{CH}_{3}\left(\mathrm{CH}_{2}\right)_{11} \mathrm{OSO}_{3} \mathrm{Na}$, a general anionic surface active substance purchased from Merck company, has an analytical purity with a molecular weight of $288.38 \mathrm{~g} / \mathrm{mole}$. MGS-L285 ${ }^{\circledR}$ di glycidyl ether of bisphenol-A (DGEBA) resin and MGS-H $2855^{\circledR}$ curing agent were purchased from Momentive (Hexion). High-strength carbon material as the fiber production material from $615 \mathrm{~g} /$ $\mathrm{m}^{2}$ nominal weight with $2 \times 2$ in the form twill weave fiber diameter of 6-7 $\mu \mathrm{m}$ and a fiber bundle $12 \mathrm{k}$ were purchased from carbon fiber fabric Techel Company.

\subsection{Electrospinning of MWCNT reinforced PVA nanofiber mats}

Solution preparation was started with PVA attainment. As shown in figure $1,10 \mathrm{~g}$ of PVA powder $(10 \% \mathrm{w} / \mathrm{w})$ was added into $90 \mathrm{~g}$ of pure water, which was heated up to $70^{\circ} \mathrm{C}$ slowly. This mixture was mixed by a magnetic mixer for $3 \mathrm{~h}$ and complete dissolution of PVA was achieved. A solution was prepared with $1 \mathrm{~g}$ of surface active substance, sodium dodecyl sulphate (SDS) and $99 \mathrm{~g}$ of pure water and mixed in a magnetic mixer for 10 min. 1,3 and $5 \%$ in weight by MWCNT per $10 \mathrm{~g}$ of PVA was added into PVASDS solution. The final solution was mixed in an ice bath for $5 \mathrm{~min}$ with 15-minute intervals through a probe homogenizator [24].
Spinning parameters were selected as: rate of mixture was $1.30 \mathrm{ml} / \mathrm{h}$, distance between collector and syringe was $12 \mathrm{~cm}$, power was $25 \mathrm{kV}$, collecting drum was rotated horizontally and $5 \mathrm{ml}$ mixture was used while manufacturing the nanofibers. These nanofibers were collected on Aluminum foil on to drum. The manufacturing was carried out at room temperature of $25^{\circ} \mathrm{C}$. Fiber samples obtained were dried in a drying-oven at $60^{\circ} \mathrm{C}$ for $1 \mathrm{~h}$.

\subsection{Preparation of CFRE composite laminates}

Considering the number of layers present in typical aircraft bodies (8-16) [25], 8 layers of composites were deemed suitable and 8 pieces of carbon fiber fabric were cut at $320 \times 320 \mathrm{~mm}^{2}$ dimensions. First, a mold release agent is applied onto a tile measuring $450 \times 450 \mathrm{~mm}^{2}$ (figure 2). Double-sided vacuum tape measuring $350 \times 350 \mathrm{~mm}^{2}$ is glued. Next, the release film, the distributor netting and the peeling fabric are placed. Pre-cut 8-layer carbon fiber fabrics are weighed in scales. Next, calculated with this amount weighed as the fiber/matrix ratio is 0.43 . The epoxy + curing ratio was taken as $100 / 25$.

The prepared epoxy resin is applied homogeneously with the help of a spatula by pouring a certain amount onto the separator fabric. One layer of $320 \times 320 \mathrm{~mm}$ carbon fabric was placed on the top of these layers and 25 grams of epoxy resin on carbon fiber fabric was applied in the same way and homogenously with the spatula. 4 layers of carbon fiber cloth is applied with epoxy resin in this way. After that, pre-produced PVA nanofiber mats are laid on the 4th layer of carbon fabric. After that, 4 layers of carbon fabrics are placed on the PVA nanofiber mats in the same manner again. Later on, the peeling fabric and the distributing net are laid again on the carbon fiber fabrics. Finally, a vacuum bag is placed on all the layers and a vacuum of 0.7 bar is taken intermittently. The composite material in vacuum is kept in the oven at $45^{\circ} \mathrm{C}$ for $1 \mathrm{~h}$ for the first curing process. For post curing process, it is done at $80^{\circ} \mathrm{C}$ for $15 \mathrm{~h}$ and production is finished.

\subsection{Characterization}

2.4a Three-point flexural test: According to ASTM D7264/7264M-15 standard and procedure A, three-point bending tests were carried out on Shimadzu AGS-X universal tester to samples of $110 \mathrm{~mm} \times 13 \mathrm{~mm} \times 4.5 \pm$ $0.2 \mathrm{~mm}$ in size crosshead speed of $1 \mathrm{~mm} / \mathrm{min}$ at room temperature. For the reliability of the results, five samples having the same contents were tested. Experiments were carried out at a support span of $90 \mathrm{~mm}$ between supports with a standard span to thickness ratio of 20:1. Figure 3 shows the loading condition of the sample from three points. 


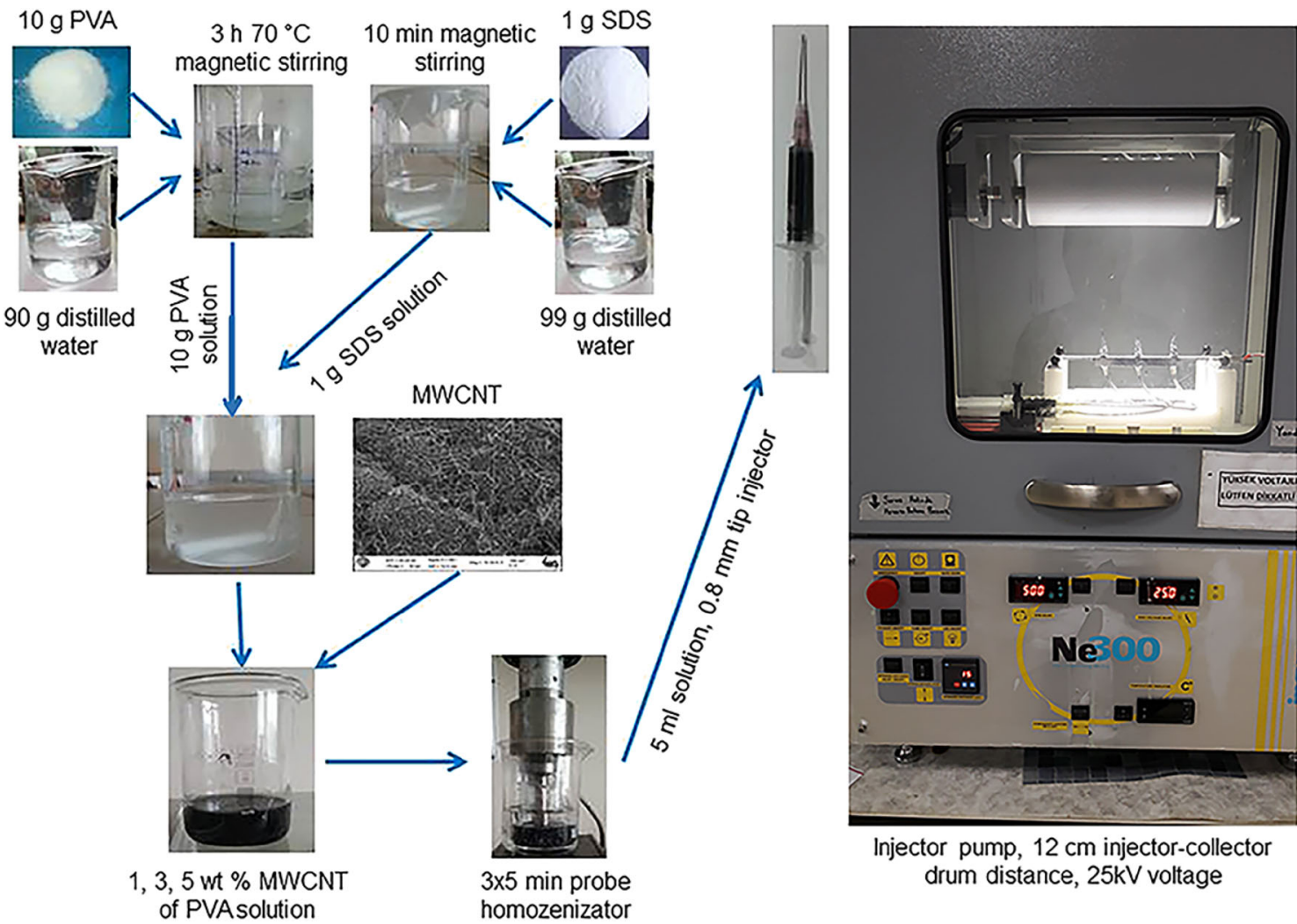

Figure 1. Schematic representation of PVA nanofiber mats manufacture procedure.
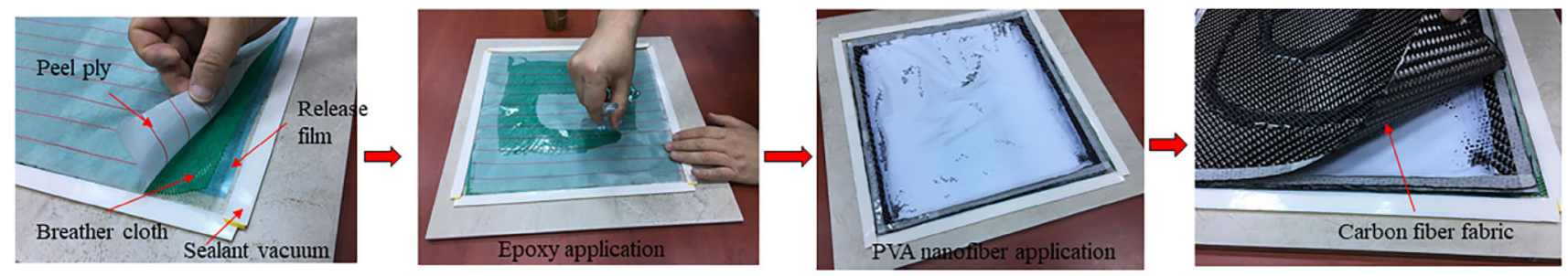

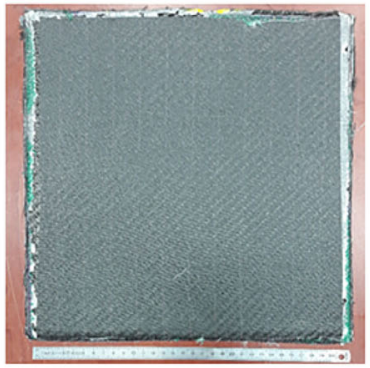

PVA nanofiber reinforced composite materials

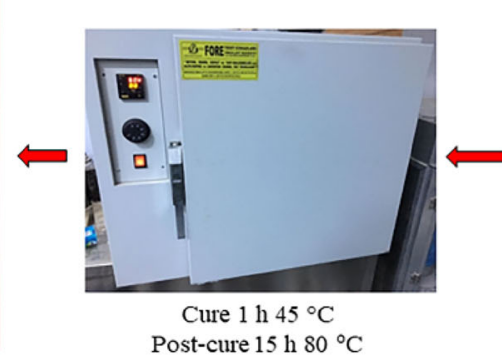

Post-cure $15 \mathrm{~h} 80^{\circ} \mathrm{C}$

Figure 2. Production of PVA reinforced carbon composite laminates by vacuum-assisted hand lay-up method.

Force, $\mathrm{P}$ and deflection, and $\delta$ values were measured and recorded by the tester instantaneously and a force-deflection diagram was created. In the three-point bending test, the maximum stress occurs at the outermost portions of the midpoint of the beam. The stress at any point of the forcestrain graph is calculated according to $\sigma=3 \cdot P \cdot L / 2 \cdot b \cdot h^{2}$. 
It is shown that, $\sigma$, stress at the outer surface in the load span region $(\mathrm{MPa}) ; \mathrm{P}$, applied force $(\mathrm{N})$; L, support span $(\mathrm{mm}) ; \mathrm{b}$, width of beam (mm); h, thickness of beam $(\mathrm{mm})$.

The maximum unit strain also occurs in the outermost parts of the sample's midpoint. The strain is calculated according to $\varepsilon=6 \cdot \delta \cdot h / L^{2}$. Where:

$\varepsilon=$ maximum strain at the outer surface, $\mathrm{mm} / \mathrm{mm}$,

$\mathrm{L}=$ support span, $\mathrm{mm}$,

$\mathrm{h}=$ thickness of beam, $\mathrm{mm}$

$\delta=$ mid-span deflection, $\mathrm{mm}$. 2.4b Tensile test: According to ASTM D3039/3039M-14 standard, tensile tests of composite materials were carried out on Shimadzu AGS-X universal tester on samples of $250 \mathrm{~mm} \times 25 \mathrm{~mm} \times 4.5 \pm 0.2 \mathrm{~mm}$ at a constant crosshead speed of $2 \mathrm{~mm} / \mathrm{min}$ and at room temperature. For reliability of the results, five samples with the same contents were tested. Sandpaper is placed between the sample and the holders to prevent the sample from sliding between the holders.

The force applied to the sample, $\mathrm{P}$, and the elongation at the sample were measured and recorded by the tester

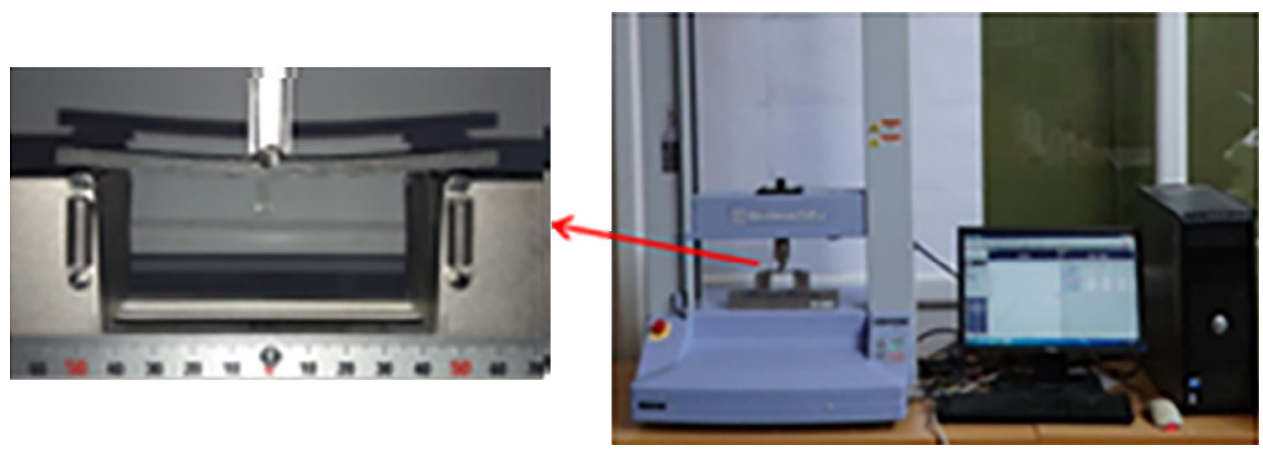

Figure 3. Three-point flexural test.
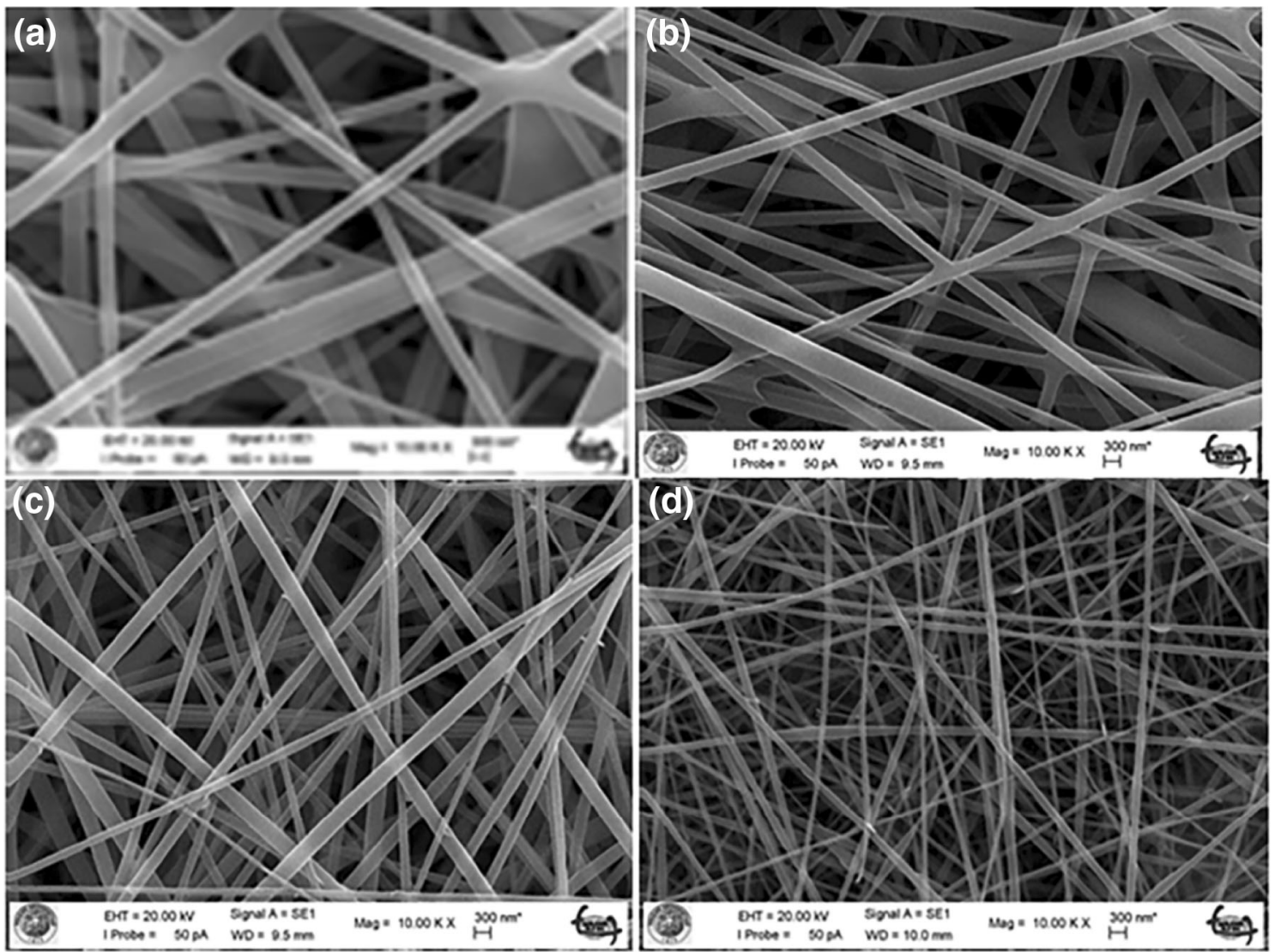

Figure 4. $10 \mathrm{KX}$ SEM imagines (a) PVA nanofiber mats, (b) $1 \%$ MWCNT/PVA nanofiber mats, (c) $3 \%$ MWCNT/PVA nanofiber mats, (d) $5 \% \mathrm{MWCNT/PVA}$ nanofiber mats. 

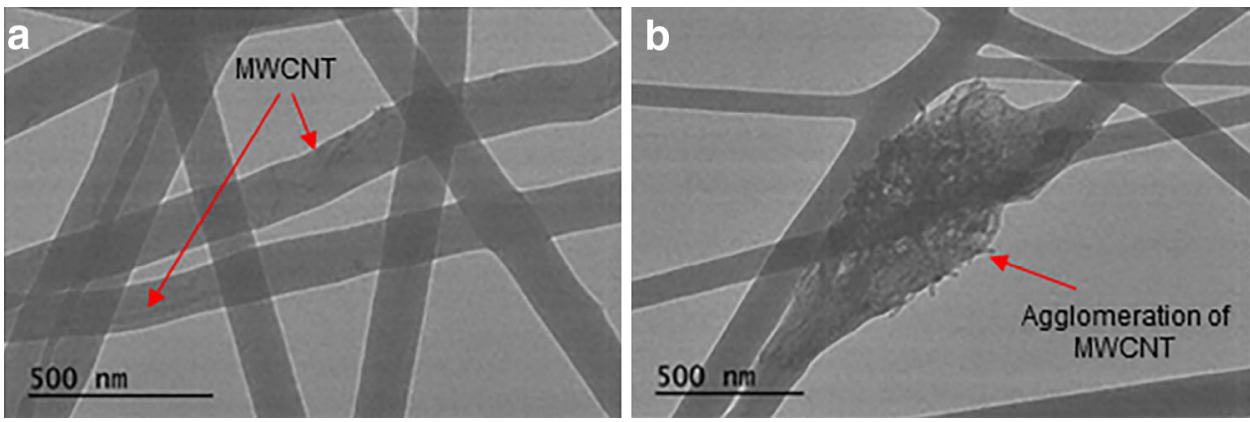

Figure 5. TEM images, (a) $3 \% \mathrm{MWCNT/PVA}$ and (b) 5\% MWCNT/PVA.

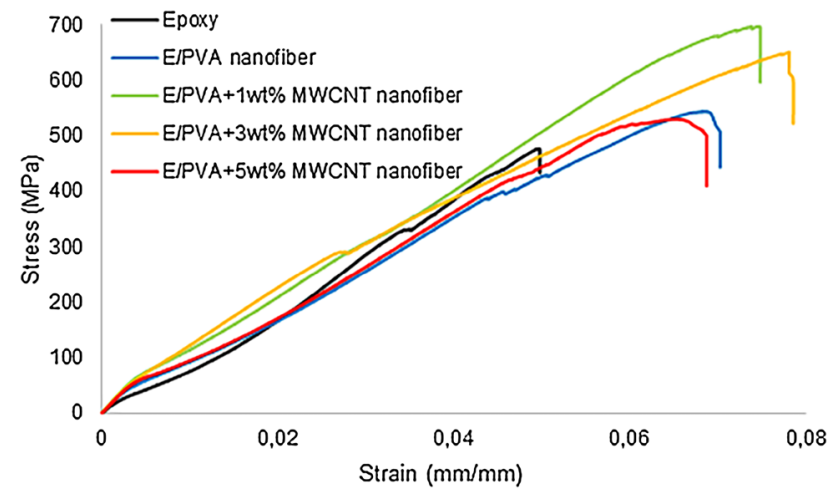

Figure 6. Stress-strain graph for MWCNT strengthen PVA nanofiber mats carbon fiber reinforced epoxy composites.

instantaneously. The tensile strength at any force value was calculated according to $\sigma_{i}=\frac{P_{i}}{A}$ and the tensile strength was calculated according to $\sigma_{\max }=\frac{P_{\max }}{A}$. Where: $\sigma_{\mathrm{i}}$, is the stress for $\mathrm{i}$ th force $(\mathrm{MPa}), \mathrm{P}_{\mathrm{i}}$, i'th data point force $(\mathrm{N}), \mathrm{A}$, crosssectional area $\left(\mathrm{mm}^{2}\right), \sigma_{\max }$, maximum tensile stress in sample (tensile strength) (MPa), $\mathrm{P}_{\max }$, indicates the maximum load that the sample can carry.

2.4c SEM and TEM images analyses: The PVA nanofiber mats were conducted by a Hitachi-SU 1510 Scanning Electron Microscope (SEM). Before SEM analysis, the PVA nanofiber mats were coated with gold for obtaining conductive surface by using Eiko 1B-3 ion coater.

MWCNT reinforced PVA nanofiber mats were taken with high magnification TEM images 2100 (UHR) device.

\section{Results and discussion}

\subsection{Morphology of MWCNT reinforced PVA nanofiber mats membrane}

As seen in figure 4, MWCNT reinforced PVA nanofiber mats SEM images were produced at a magnification of $10000 \times$ and a voltage of $20 \mathrm{kV}$. Furthermore, SEM images were pasted into AutoCAD program and the smallest and
Table 1. Tensile properties of carbon fiber reinforced epoxy composites.

\begin{tabular}{lccccc}
\hline Sample & $\begin{array}{c}\text { Load* } \\
(\mathrm{kN})\end{array}$ & $\begin{array}{c}\text { Stress* } \\
(\mathrm{MPa}) \\
\left(\mathrm{SD}^{* *}\right)\end{array}$ & $\begin{array}{c}\text { Strain } \\
(\mathrm{mm} / \\
\mathrm{mm})\end{array}$ & $\begin{array}{c}\text { Elasticity } \\
\text { modulus } \\
(\mathrm{GPa})\end{array}$ & $\begin{array}{c}\text { Toughness } \\
\left.\left(\mathrm{J}^{3}\right)^{3}\right)\end{array}$ \\
\hline CFRE & 55.8 & $487(33)$ & 0.050 & 12.9 & 11.9 \\
PVA & 61.9 & $508(45)$ & 0.070 & 9.9 & 19.1 \\
1\%CNT & 78.0 & $653(31)$ & 0.075 & 11.5 & 26.1 \\
3\%CNT & 76.0 & $575(62)$ & 0.079 & 11.8 & 25.6 \\
5\%CNT & 58.8 & $530(20)$ & 0.069 & 10.3 & 18.2 \\
\hline
\end{tabular}

**SD: \pm standard deviation; *Arithmetic mean values.

largest 10 diameters of each nanofiber mat were measured and average was calculated. Diameter measurements of PVA nanofiber mats were measured between 222 and $403 \mathrm{~nm}$; diameter measure of $1 \%$ MWCNT/PVA nanofiber mats was measured between 154 and $335 \mathrm{~nm}$; diameter measure of 3\% MWCNT/PVA nanofiber mats was measured between 117 and $265 \mathrm{~nm}$ and diameter measure of $5 \%$ MWCNT/PVA nanofiber mats was measured between 95 and $192 \mathrm{~nm}$.

When figure 4 is examined, it is seen that diameters of nanofiber mats decrease as MWCNT added into the PVA solution increases due to MWCNT conductivity, resulting in thin fibers. However, increasing MWCNT quantity, agglomeration and viscosity make it difficult to pump solution from the syringe and causes agglomeration. Interruptions appear in fiber lengths.

As seen in figure 5, TEM images show multi-walled carbon nanotubes added to nanofibers. When TEM images are compared with SEM images, the results are mutually supportive. When TEM images are examined, MWCNTs cannot be seen because 1\% MWCNT/PVA nanofiber mats have a low ratio in reinforced nanofibers. In the $3 \%$ MWCNT/PVA nanofiber mats reinforced nanofibers, it is seen that the MWCNTs are homogeneously dispersed and placed in the nanofibers (see figure 5a). In the case of the 5\% MWCNT/PVA nanofiber mats reinforced nanofibers shown in figure $5(\mathrm{~b})$, it is observed that the agglomerates 
are more clotted and the MWCNTs are distributed evenly. These agglomerated regions exhibit the discontinued behavior of nanofiber mats.

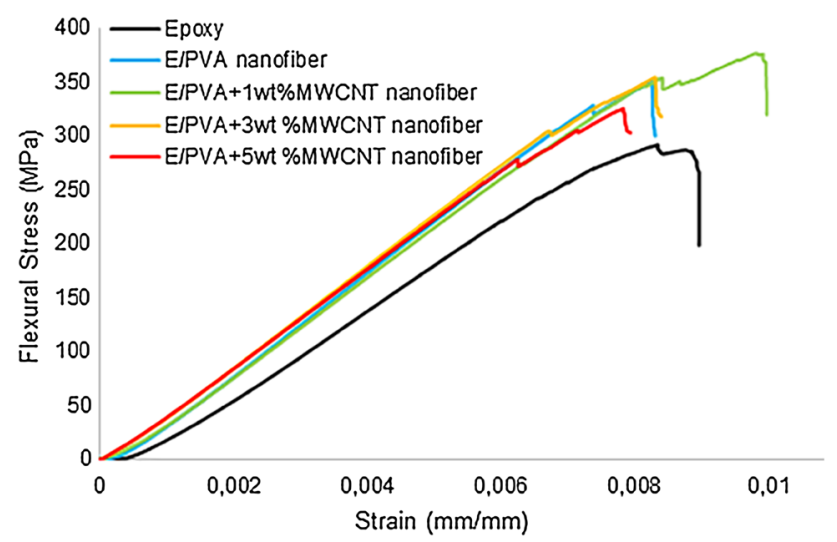

Figure 7. Flexural stress-strain graph for MWCNT strengthened PVA nanofiber mats carbon fiber reinforced epoxy composites

Table 2. Flexural properties of carbon fiber reinforced epoxy composites.

\begin{tabular}{lcccc}
\hline Sample & $\begin{array}{c}\text { Load* } \\
(\mathrm{kN})\end{array}$ & $\begin{array}{c}\text { Stress* } \\
(\mathrm{MPa}) \\
\left(\mathrm{SD}^{* *}\right)\end{array}$ & $\begin{array}{c}\text { Strain } \\
(\mathrm{mm} / \\
\mathrm{mm})\end{array}$ & $\begin{array}{c}\text { Flexural elasticity } \\
\text { modulus }(\mathrm{GPa})\end{array}$ \\
\hline CFRE & 588.0 & $267(17)$ & 0.0090 & 41.7 \\
PVA & 702.1 & $324(19)$ & 0.0083 & 46.1 \\
1\%CNT & 708.3 & $350(18)$ & 0.0099 & 46.7 \\
$3 \% \mathrm{CNT}$ & 714.1 & $345(12)$ & 0.0084 & 46.7 \\
$5 \% \mathrm{CNT}$ & 655.7 & $333(11)$ & 0.0079 & 46.3 \\
\hline
\end{tabular}

**SD: \pm standard deviation; *Arithmetic mean values.

\subsection{Tensile properties of composite laminates}

Figure 6 shows the tensile-strain diagrams of the MWCNTreinforced PVA nanofiber mats carbon fiber reinforced epoxy composites obtained under constant load tensile tests. Tensile strengths and load capacities of PVA nanofiber mats reinforced carbon fiber reinforced epoxy composite are different in terms of MWCNT weight. The tensile strengths of 1 and 3\% MWCNT/PVA nanofiber mats strengthen carbon fiber reinforced epoxy composites were found to be 653 and $575 \mathrm{MPa}$, respectively. The tensile strengths of 1 and 3\% MWCNT/PVA nanofiber mats reinforced CFRE composites increased by 34 and $18 \%$, respectively, when compared to the CFRE composite.

Table 1 presents the mechanical properties of CFRE and MWCNT reinforced/unreinforced PVA nano-fiber mats composite materials at different ratios. The maximum load, stress, strain, modulus of elasticity and ductility of the CFRE composites were found to be $55.8 \mathrm{kN}, 487 \mathrm{MPa}$, $0.050 \mathrm{~mm} / \mathrm{mm}, 12.9 \mathrm{GPa}$ and $11.9 \mathrm{~J} / \mathrm{m}^{3}$, respectively. The load, stress and toughness of $1 \mathrm{wt} \%$ MWCNT/PVA nanofiber mats reinforced carbon fiber reinforced epoxy composites increased by 40,34 and $119 \%$, respectively, when compared with CFRE.

\subsection{Flexural properties of composite laminates}

In figure 7, MWCNT PVA nanofiber mats reinforced with carbon fiber reinforced epoxy composites under constant load changes resulting from the flexural stress-strain graph of three-point flexural test are given. The flexural strength of the CFRE composites was $267 \mathrm{MPa}$, while the flexural strength of $1 \mathrm{wt} \%$ MWCNT/PVA nanofiber mats reinforced carbon fiber reinforced epoxy composites was 350 MP with an increase of $31 \%$.
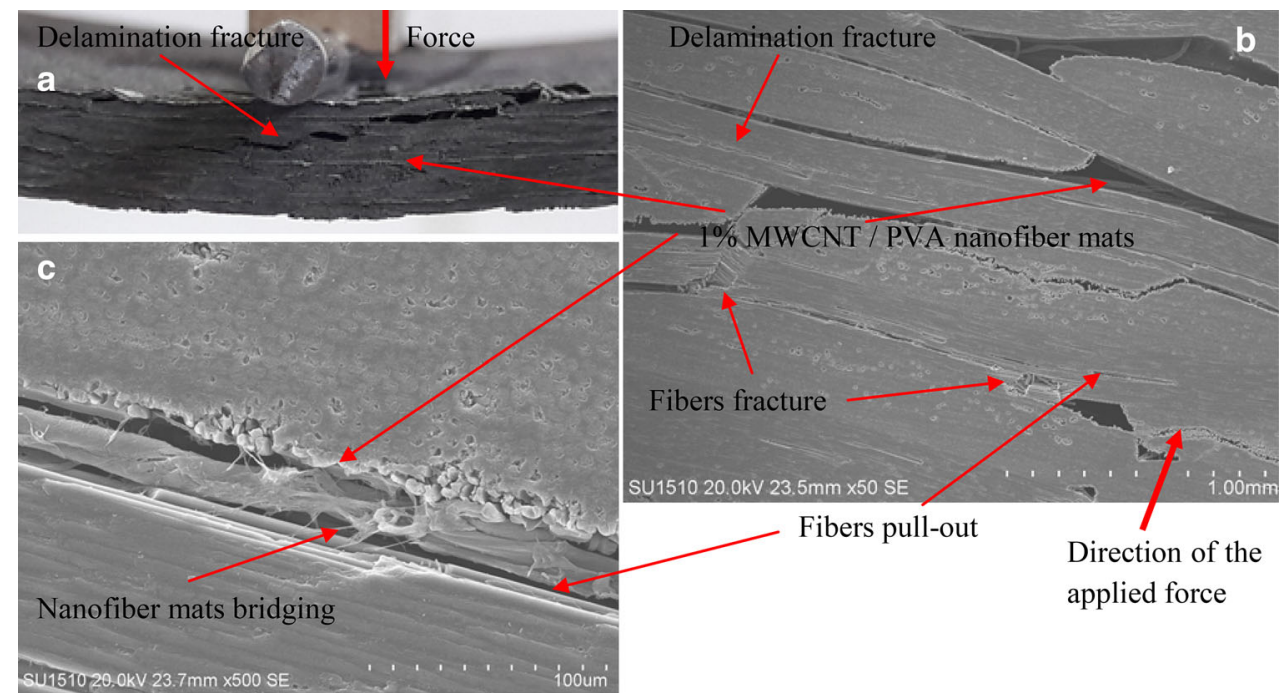

applied force

Figure 8. SEM images of (a) Delamination of matrix, (b) Fiber fracture and pull-out and (c) Bridging of nano fibers. 
Table 2 gives the flexural properties of CFRE and MWCNT reinforced/unreinforced PVA nanofiber mats composite materials at different ratios. The maximum load, stress, flexural strain and flexural modulus of the CFRE composites were found to be $588.0 \mathrm{kN}, 267 \mathrm{MPa}$, $0.0090 \mathrm{~mm} / \mathrm{mm}$ and $41.7 \mathrm{GPa}$, respectively. The load, flexural strain and flexural elasticity modulus of $1 \%$ MWCNT/PVA nanofiber mats reinforced carbon fiber reinforced epoxy composites increased by 20,10 and $12 \%$, respectively, when compared with CFRE.

\subsection{SEM images of fractured surfaces after the flexural tests}

Because of the anisotropic and heterogeneous structure, fiber reinforced composite layers can exhibit four different failure modes. These modes are matrix fracture, the fracture between the layers, fiber fracture and pull-out of the fibers. Determining the failure modes into a material is not only important to understand the impact but also important to get information about the resultant strength of a material. The interaction between the failure modes is also important by a view of the start and developing a failure. Failure mechanisms into $1 \%$ MWCNT/PVA nanofiber mats reinforced carbon fiber reinforced epoxy composites are shown in figure 8 .

\section{Conclusion}

In this study, membranes of networked PVA nanofiber mats with reinforced 1,3 and $5 \mathrm{wt} \%$ MWCNT's ratio were interleaved into the ply-interfaces of CFRE composite laminates with the aim to investigate tensile and flexural properties.

First, SEM and TEM images of MWCNT-reinforced PVA nanocomposite matrices weighting $1,3,5 \%$ were investigated. The increase in the amount of MWCNT is seen in the SEM pictures of the nanofiber mats with their diameters decreasing. However, as the solution increases in viscosity due to the increase of MWCNT, the aggregation of MWCNTs and the discontinuity in nanofibers increase, as observed in TEM images.

The MWCNT-reinforced PVA nanocomposite mats were then placed between the Carbon Fiber Reinforced Epoxy Composites, showing a $34 \%$ and $50 \%$ increase in tensile strength and strain, respectively. Then the flexural test was carried out and the flexural strengths and flexural modulus were investigated. The MWCNT-reinforced PVA nanofiber mats are placed in the slip center of the CFRE composite to improve the bending properties of the material by preventing delamination and increasing bonding. Mechanical property improving can be concluded because of the bridging effect of the nanofiber mats.
This study contributes to the knowledge about the effect of MWCNT a strengthened PVA nanofiber mat in CFRE composite laminates. It gives more insight to the static tensile and flexural behavior of such composites. And it draws important conclusions regarding the influence of MWCNT strengthened PVA nanofiber mats interleaving on some mechanical properties of CFRE laminates. It also provides information on the distribution of MWCNTs in the PVA nanofiber mats.

\section{Acknowledgements}

Author thanks for the financial support given by Scientific and Technological Research Council of Turkey (TUBITAK Project: 215M777) and the Scientific Research Projects Coordinator (No. 161219006) of Necmettin Erbakan University.
Nomenclature
CFRE Carbon Fiber Reinforced Epoxy
MWCNT Multiwalled Carbon Nanotubes
PVA Polyvinyl Alcohol
TEM Transmission Electron Microscopy
SEM Scanning Electron Microscopy
SDS Sodium Dodecyl Sulphate
DGEBA Di Glycidyl Ether of Bisphenol-A

\section{References}

[1] Ekrem M 2015 Fracture Behavior of Epoxy Adhesives Reinforced with Carbon Nanotubes and Polyvinyl Alcohol Nanofibers in Aluminum Joints. PhD Dissertation, Selcuk University, Konya

[2] Kim J-K and Mai Y W 1998 Engineered interfaces in fiber reinforced composites; Elsevier, UK

[3] Erkendirci O F, Avci A and Ekrem M 2010 Investigation of the Fracture Behavior of Woven Fiber Glass-reinforced Lowdensity Polyethylene Composite. Journal of Composite Materials 44: 2697-2709

[4] Ozkan T, Chen Q and Chasiotis I 2012 Interfacial strength and fracture energy of individual carbon nanofibers in epoxy matrix as a function of surface conditions. Composite Science and Technology 72: 965-975

[5] Zhang D, Cabrera E, ZhaoY, Zhao Z, Castro J M and Lee L J 2017 Improved sand erosion resistance and mechanical properties of multifunctional carbon nanofiber nanopaperenhanced fiber reinforced epoxy composites. Advances in Polymer Technology

[6] Ozkan T, Shaddock D, Lipkin D M and Chasiotis I 2014 Mechanical strengthening, stiffening, and oxidation behavior of pentatwinned $\mathrm{Cu}$ nanowires at near ambient temperatures. Mater. Res. Express 1

[7] Wang C H, Sidhu K, Yang T, Zhang J and Shanks R 2012 Interlayer self-healing and toughening of carbon fibre/epoxy 
composites using copolymer films. Composites Part A: Applied Science and Manufacturing 43: 512-518

[8] Ulus H, Ustun T, Eskizeybek V, Sahin O S, Avci A and Ekrem M 2014 Boron nitride-MWCNT/epoxy hybrid nanocomposites: Preparation and mechanical properties. Applied Surface Science 318: 37-42

[9] Shekar K C, Prasad B A and Prasad N E 2016 Strengthening in and fracture behaviour of CNT and carbon-fibre-reinforced epoxy-matrix hybrid composite. SADHANA - Academy Proceedings in Engineering Sciences 41: 1443-1461

[10] Khare P and Verma N 2015 A novel alumina nanoparticlecarbon micro-nanofiber-polypropylene nanocomposite with improved electrical, thermal, and mechanical properties. Polymer Composites 38(S1): E359-E370

[11] Ekrem M and Avc1 A 2018 Effects of polyvinyl alcohol nanofiber mats on the adhesion strength and fracture toughness of epoxy adhesive joints. Composites Part B: Engineering, 138: 256-264

[12] Alharbi H F, Luqman M, Fouad H, Khalil K A and Alharthi N H 2018 Viscoelastic behavior of core-shell structured nanofibers of PLA and PVA produced by coaxial electrospinning. Polymer Testing 67: 136-143

[13] Naebe M, Lin,T, Staiger M P, Dai L M and Wang X G 2008 Electrospun single-walled carbon nanotube/polyvinyl alcohol composite nanofibers: structure-property relationships. Nanotechnology 19(30): 305702

[14] Daelemans L, van der Heijden S, De Baere I, Rahier H, Van Paepegem W and De Clerck K 2016 Using aligned nanofibres for identifying the toughening micromechanisms in nanofibre interleaved laminates. Compos. Sci. Technol. 124: $17-26$

[15] Zheng N, Huang Y D, Liu H Y, Gao J F and Mai Y W 2017 Improvement of interlaminar fracture toughness in carbon fiber/epoxy composites with carbon nanotubes/polysulfone interleaves. Compos. Sci. Technol. 140: 8-15

[16] Khan S U and Kim J K 2012 Improved interlaminar shear properties of multiscale carbon fiber composites with bucky paper interleaves made from carbon nanofibers. Carbon 50:5265-5277

[17] van der Heijden S, Daelemans L, De Schoenmaker B, De Baere I, Rahier H, Van Paepegem W and De Clerck K 2014 Interlaminar toughening of resin transfer moulded glass fibre epoxy laminates by polycaprolactone electrospun nanofibres. Compos. Sci. Technol. 104: 66-73

[18] Shivakumar K, Lingaiah S, Chen H C, Akangah P, Swaminathan G and Russell L 2009 Polymer Nanofabric Interleaved Composite Laminates. AIAA J. 47: 1723-1729

[19] Akangah P and Shivakumar K 2013 Assessment of impact damage resistance and tolerance of polymer nanofiber interleaved composite laminates. Journal of Chemical Science and Technology 2: 39-52

[20] Ahmadi-Moghadam B and Taheri F 2015 Influence of graphene nanoplatelets on modes I, II and III interlaminar fracture toughness of fiber-reinforced polymer composites. Engineering Fracture Mechanics 143: 97-107

[21] Phong N T, Gabr M H, Okubo K, Chuong B, and Fujii T 2013 Improvement in the mechanical performances of carbon fiber/epoxy composite with addition of nano-(Polyvinyl alcohol) fibers. Compos. Struct. 99: 380-387

[22] Zhang C M, Li H, Zhuo Z Z, Dugnani R, Xue W C, Zhou Y, Chen Y J and Liu H Z 2017 Characterization of the damping and mechanical properties of a novel $\left(\mathrm{ZnSnO}_{3} / \mathrm{PVDF}\right) @ \mathrm{PPy}$ nanofibers/EP composite. Rsc Advances 7: 37130-37138

[23] Diouri N and Baitoul M 2014 Effect of carbon nanotubes dispersion on morphology, internal structure and thermal stability of electrospun poly (vinyl alcohol)/carbon nanotubes nanofibers. Optical and Quantum Electronics 46: 259-269

[24] Ekrem M 2017 Mechanical properties of MWCNT Reinforced polyvinyl alcohol nanofiber mats by electrospinnig method. El-Cezeri Journal of Science and Engineering 4(2): 190-200

[25] York C B 2017 On Bending-Twisting coupled laminates. Compos. Struct. 160: 887-900 